\title{
Approaches Mediating Oxytocin Regulation of the Immune System
}

\author{
Tong $\mathrm{Li}^{1 \dagger}$, Ping Wang ${ }^{1 \dagger}$, Stephani C. Wang ${ }^{2}$ and Yu-Feng Wang ${ }^{1 *}$ \\ 1 School of Basic Medical Sciences, Harbin Medical University, Harbin, China, ${ }^{2}$ Department of Internal Medicine, Albany \\ Medical Center, Albany, NY, USA
}

OPEN ACCESS

Edited by:

Kai Fang,

University of California

Los Angeles, USA

Reviewed by:

Honoo Satake,

Suntory, Japan

Salvatore Andrea Mastrolia,

University of Bari, Italy

Vincent Geenen,

University of Liège, Belgium

*Correspondence:

Yu-Feng Wang

yufengwang@ems.hrbmu.edu.cn

these authors have contributed equally to this work.

Specialty section:

This article was submitted to Inflammation,

a section of the journal

Frontiers in Immunology

Received: 13 November 2016

Accepted: 28 December 2016

Published: 10 January 2017

Citation:

Li T, Wang P, Wang SC and Wang Y-F (2017) Approaches Mediating Oxytocin Regulation of the Immune System.

Front. Immunol. 7:693. doi: 10.3389/fimmu.2016.00693
The hypothalamic neuroendocrine system is mainly composed of the neural structures regulating hormone secretion from the pituitary gland and has been considered as the higher regulatory center of the immune system. Recently, the hypothalamo-neurohypophysial system (HNS) emerged as an important component of neuroendocrine-immune network, wherein the oxytocin (OT)-secreting system (OSS) plays an essential role. The OSS, consisting of OT neurons in the supraoptic nucleus, paraventricular nucleus, their several accessory nuclei and associated structures, can integrate neural, endocrine, metabolic, and immune information and plays a pivotal role in the development and functions of the immune system. The OSS can promote the development of thymus and bone marrow, perform immune surveillance, strengthen immune defense, and maintain immune homeostasis. Correspondingly, OT can inhibit inflammation, exert antibiotic-like effect, promote wound healing and regeneration, and suppress stress-associated immune disorders. In this process, the OSS can release OT to act on immune system directly by activating OT receptors or through modulating activities of other hypothalamic-pituitary-immune axes and autonomic nervous system indirectly. However, our understandings of the role of the OSS in neuroendocrine regulation of immune system are largely incomplete, particularly its relationship with other hypothalamic-pituitary-immune axes and the vasopressin-secreting system that coexists with the OSS in the HNS. In addition, it remains unclear about the relationship between the OSS and peripherally produced OT in immune regulation, particularly intrathymic OT that is known to elicit central immunological self-tolerance of T-cells to hypophysial hormones. In this work, we provide a brief review of current knowledge of the features of OSS regulation of the immune system and of potential approaches that mediate OSS coordination of the activities of entire neuroendocrine-immune network.

Keywords: cytokine, hormone, hypothalamus, immune, oxytocin, thymus

\section{INTRODUCTION}

Immune activities are regulated by many factors, such as the genetic individual variations, immune cytokine, hormone, emotion, nutrition, metabolism, sleep, age, neural activity, and pathogens. Among them, neuroendocrine regulation of immune system is the fundamental machinery $(1,2)$. Recently, the hypothalamic oxytocin (OT)-secreting system (OSS) has emerged as a pivotal factor in neuroendocrine regulation of immune activities (3). However, its relationship with other 
hypothalamic-pituitary-immune axes as well as peripherally produced OT remains unclear, which is further explored in this review.

\section{NEUROENDOCRINE-IMMUNE NETWORK AND THE OSS}

\section{The Neuroendocrine-Immune Network}

As early as 1977, the existence of a neural-endocrine-immune network has been proposed (4). In this network, immune activity can influence the development (5) and functions (6) of rat hypothalamus, the higher control center of the neuroendocrine system. Conversely, changes in neuroendocrine activities can affect the immune response through pituitary tropic hormones and the autonomic nervous system (7). This bidirectional communication between hypothalamic neuroendocrine system and the immune system forms a neuroendocrine-immune network.

\section{The OSS-Immune Network}

In the neuroendocrine-immune network, immune regulatory roles of the hypothalamo-neurohypophysial system (HNS) (8), particularly its OSS, have been considered critical (3). The OSS is mainly composed of magnocellular OT neurons in the supraoptic nucleus (SON), paraventricular nucleus (PVN), and several accessory nuclei of the hypothalamus as well as their axon terminals in the posterior lobe of the pituitary. In addition, parvocellular OT neurons in the PVN, a major source of OT in the brain and spinal cord, coexist with corticotropin-releasing hormone (CRH) and thyrotropin-releasing hormone (TRH) neurons in the PVN while closely interacting with magnocellular OT neurons (9) and the autonomic center that can regulate immune activity through sympathetic nervous system (10). In this OSS-immune network, the magnocellular OT neurons in the SON play a dominant role in response to immune challenges as shown in rat sepsis (11).

\section{CHARACTERISTICS OF THE OSS-IMMUNE NETWORK}

\section{The OSS Is Involved in the Development and Functions of the Central Immune Organs}

It has been reported that neurointermediate pituitary lobectomy, blocking the secretion of neurohypophysial hormones including OT, significantly changed humoral and cellular immune responses in rats $(12,13)$. OT can also promote the formation of human hematopoietic stem cells (14) and promote rat bone marrow mesenchymal stem cell migration (15). Moreover, blocking OT receptor (OTR) signaling can inhibit the differentiation of mouse thymic T-cells (16) and estrogen-evoked bone formation (17) while increasing the expression and secretion of inflammatory cytokines, such as interleukin (IL)-6 in human amnion (18). Thus, OT is a key regulator of the immune system and thus can extensively regulate immune activity (3), which is considered to be mediated by OTRs as summarized in Table $\mathbf{1}$.

\section{The OSS Bidirectionally Communicates with the Immune System through Multiple Approaches}

Oxytocin can regulate immune functions (37) by activating OTRs directly (3) and through sympathetic outflow $(10,50)$ that is known to control the activity of rat thymus (51) and bone marrow (52). OT can also change the activity of other hypothalamic-pituitary-immune axes (Figure 1A). Conversely, the OSS is also the target of immune diseases. For example, OT neurophysin shares an antigen with human lung carcinoma LX-1 cells (53); OT neurons are a major target of many autoimmune diseases such as multiple sclerosis $(45,54)$; OT in hypothalamic neurons decreased in HIV-infected patients (55). In response to immune challenges, IL-6 (50) and IL-1 $\beta$ (56) can activate rodent OT neurons in the PVN and/or SON, while microglia in the PVN can increase OT secretion and sympathetic activity (57). Thus, the OSS can regulate immune activity more accurately.

\section{OT Neurons Are "Immune Cells" and Mainly Function through OTRs}

Oxytocin neurons can produce cytokines such as IL-1 $\beta$ (58), nitric oxide $(59)$, and prostaglandins $(60,61)$ in rats. These cytokines can not only autoregulate OT neuronal activity, such as nitric oxide (62) and prostaglandins (61) in rats, but also extensively modulate immune activity of other brain structures (63) (Figure 1A).

Both the OSS and the immune system can synthesize and release neurotransmitters, neuropeptides, and cytokines while expressing receptors for both neuropeptides and immune cytokines including OT and OTRs $(1,2)$. OTRs are widely identified in immune organs, tissues, and cells, such as rat thymic epithelial cells (64) and bone marrow stem cells (19). Importantly, the expression of OTRs in immune tissues can be inducible, which has been shown in bovine peripheral blood mononuclear cells and Tymphocytes (65), rat mesenchymal stem cells (19), and gut (48). Thus, OT can modulate immune activity and immune-regulating cells directly and dynamically to meet the demands of a variety of immune challenges.

\section{The OSS Behaves As an Integrative Organ in Feedforward and Feedback Immune Loops}

Oxytocin neurons can integrate information from presynaptic neurons, detect the state of astrocytic plasticity and microglial activation, sense concentrations of blood-borne substances and local neurochemical including cytokines (3, 66-68), and in turn secrete appropriate amount of OT into the blood and brain. This could preset the immune system in an optimal working condition through regulating the activity of bone marrow, thymus, and T-/B-cells as well as other immune organs and tissues (3). In parallel, overly increased immune challenges can be suppressed through increasing OT release. For example, IL- $1 \beta$ released by immune cells can activate OT neurons or promote the release of OT into the blood in rats (69, $70)$; OT subsequently reduces the production of inflammatory cytokines as evidenced in men (37), thereby maintaining the 
TABLE 1 | Major immune functions of the oxytocin-secreting system (OSS).

\begin{tabular}{|c|c|c|c|}
\hline Sources & Targets & Effects & Reference \\
\hline \multicolumn{4}{|c|}{ Development of the immune system } \\
\hline Human, mouse & Osteoblast & Bone mass $\uparrow$ & $(17)$ \\
\hline Rat & BMSC & Intracellular $\left[\mathrm{Ca}^{2+}\right] \uparrow$ & (19) \\
\hline Rat & MSC & Apoptosis $\downarrow$ & (20) \\
\hline Rat & UCB-MSC & Migration of BMSC to the injured area $\uparrow$ & $(15,23)$ \\
\hline Parturient women & Blood & Number of B-lymphocyte $\uparrow$ & (24) \\
\hline \multicolumn{4}{|l|}{ Immune surveillance } \\
\hline Rat at early stage of sepsis & Brain, plasma & OT levels $\uparrow$, OT in the SON and neurohypophysis $\downarrow$ & (25) \\
\hline Rats with adjuvant arthritis & SON, PVN & OT mRNA $\uparrow$ & (28) \\
\hline Human lung and $\mathrm{Gl}$ tumors & Lung, liver & OTR in tumor tissues $\uparrow$ & $(29,30)$ \\
\hline Breast cancer & OT levels & Pituitary and blood $\uparrow$; cancer tissues $\downarrow$ & (31) \\
\hline \multicolumn{4}{|l|}{ Immune defense } \\
\hline Humans and animals & Immune cells, blood & $\begin{array}{l}\text { Inflammatory cytokines, e.g., nitrite, TNF- } \alpha \text {, and IL- } 1 \beta \text { levels } \downarrow \text {; oxidative stress } \downarrow \text {; apoptotic } \\
\text { pathways } \downarrow \text {; immune damages, activation of free radical damaging cascades and lactate } \\
\text { dehydrogenase } \downarrow \text {; excessive infiltration of neutrophils } \downarrow\end{array}$ & $(25,32-36)$ \\
\hline Human & Plasma & $\begin{array}{l}\text { ACTH, cortisol, procalcitonin, IL-1, IL-4, IL-6, macrophage inflammatory protein- } \mid \alpha \text { and } \\
1 \beta \text {, monocyte chemoattractant protein-1, interferon-inducible protein } 10 \text {, and vascular } \\
\text { endothelial growth factor } \downarrow\end{array}$ & (37) \\
\hline \multicolumn{4}{|l|}{ Immune homeostasis } \\
\hline Rat & DM-MSC & Angiogenic capacity & (43) \\
\hline Rabbit & Myocardial cell & Antifibrotic and angiogenic effect & (44) \\
\hline Rat and swine & Brain & Autoantibodies in multiple sclerosis are reactive with OT neurons & (45) \\
\hline Diabetic rats & Muscle, pancreas & Regenerative capacity of skeletal muscle and pancreatic islet cells $\uparrow$ & $(46,47)$ \\
\hline Caco2BB gut cells & Enterocyte & Inflammation-evoked apoptosis $\downarrow$ & (48) \\
\hline HIV-infected patients & Blood & CD4 $4^{+}$cell counts $\uparrow$ & (49) \\
\hline
\end{tabular}

ACTH, adrenocorticotropic hormone; BMSC, bone marrow stromal cells; DM-MSC, diabetic bone MSC; MSC, bone marrow mesenchymal stem cell; IL, interleukin; OT, oxytocin;

OTR, OT receptor; PVN, paraventricular nucleus; SON, supraoptic nucleus; TNF- $\alpha$, tumor necrosis factor-alpha; UCB-MSC, umbilical cord blood-derived mesenchymal stem cell.

homeostasis of immune functions and inhibiting immune damages.

\section{IMMUNE FUNCTIONS OF THE OSS}

The OSS is involved in many physiological and pathological immune processes (Table 1), which falls into the following categories.

\section{Immune Surveillance}

The OSS can detect immune states and serves as biomarker of immune challenges. For instance, it has been identified in rats that there is significant increase in plasma OT levels at the early stage of sepsis (25), brain OT release following pancreatic injury (26), OT mRNA in adjuvant arthritis (28), and Fos expression in the OSS in advanced cancer (27). Thus, increased OT levels manifest immune disturbance. 


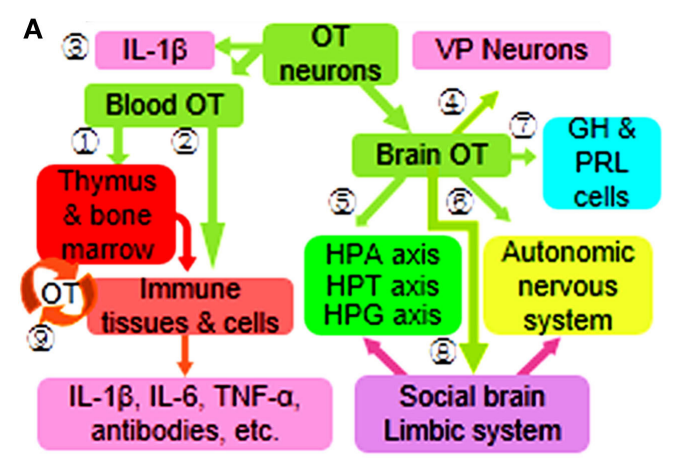

D

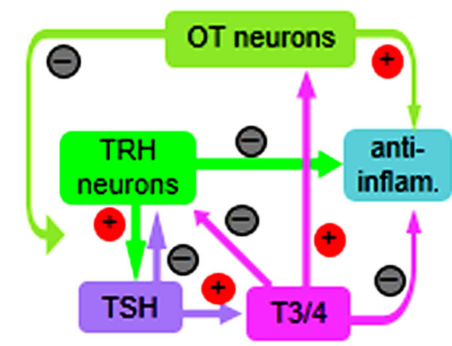

B

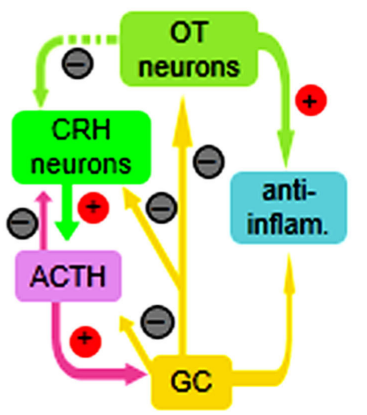

c

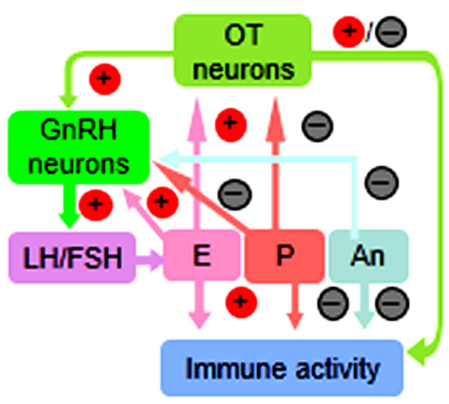

E

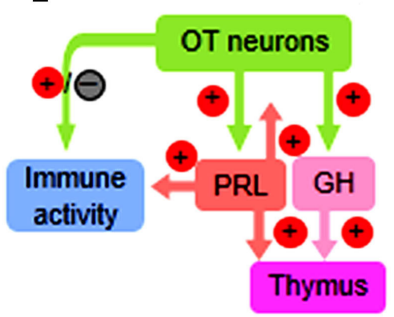

$\mathbf{F}$

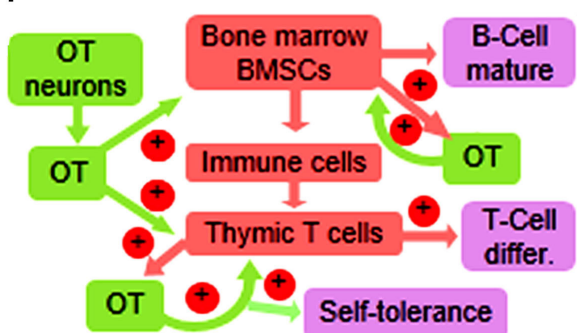

FIGURE 1 | Diagram of immune functions of the oxytocin-secreting system (OSS) through a variety of approaches. (A) Overview of the approaches. The circled numbers 1-9 represent the effects of OT on the immune system through activating peripheral OTRs on central immune organs (1) and peripheral immune organs, tissues, and cells (2); and secretion of IL-1 $\beta$ (3) as well as via centrally acting on VP neurons (4); the hypothalamic-pituitary-adrenal (HPA) axis,

hypothalamic-pituitary-thyroid (HPT) axis, and the hypothalamic-pituitary-gonadal (HPG) axis (5); autonomic nervous system (6); growth hormone (GH) and prolactin (PRL) (7); and social brain and the limbic system (8). In addition, peripherally produced OT also exerts some autoregulatory effects (9). (B) Interactions between the OSS and HPA axis. Note that plus sign in red circle and minus sign in black circle represent facilitation and inhibition, respectively; the dashed line in green indicates multiple approaches. (C) Interactions between the OSS and HPG axis. (D) Interactions between the OSS and HPT axis. (E) Interactions of the OSS with GH and PRL. (F) Synergic effects of the OSS and peripherally produced OT on the immune system. Abbreviations: ACTH, adrenocorticotropic hormone; An, androgens; differ., differentiation; inflam., inflammation; E, estrogens; FSH, follicle-stimulating hormone; GC, glucocorticoids; IL, interleukin; LH, luteinizing hormone; P, progesterone; T3/4, triiodothyronine and thyroxine; TNF- $\alpha$, tumor necrosis factor- $\alpha$; TSH, thyroid-stimulating hormone; VP, vasopressin.

\section{Strengthening Immune Defense}

Body's immune defense is carried out through multiple levels of immune machineries. OT can strengthen the physical and chemical barriers through suppressing proinflammatory cytokines (34) and promoting wound healing (39) in human skin, enforce human non-specific cellular and humoral immunity via strengthening the antibacterial effect of antibiotics (38) and accelerating migration of rat bone marrow mesenchymal stem cells to the injured area (15), and increase acquired immunity by promoting the differentiation of mouse thymic cells (16). OT was also found to alleviate harmful effects of hyperglycemia on rat peripheral neurons by suppressing inflammation, oxidative stress, and apoptotic pathways (32). As a result, activated OSS can adjust inflammatory reactions at appropriate levels to prevent body from immune damages.

\section{Maintenance of Immune Homeostasis}

A healthy individual may fall into diseases due to excessive or insufficient immune activity. Theoretically, the regulatory effects of OT on immune responses should allow OT to influence the progress of autoimmune diseases, which is supported by the finding that in women living with HIV, high levels of OT were positively associated with $\mathrm{CD} 4^{+}$cell counts (49). Moreover,
OT was found to increase the production of hematopoietic stem cells and the survival of thymic CD8 cells (22) while reducing the infiltration of neutrophils in rats $(33,36)$ and the production of human inflammatory cytokines (34). Thus, OT is critical in maintaining immune homeostasis.

\section{Other Immune Functions}

The OSS can also influence other immune processes. For example, OT can improve autism, depression, and other mental disorders associated with immune disorders (71) and increase resistance of enterocyte apoptosis (48) while reducing the apoptosis of rat mesenchymal stem cells (20), and promoting regenerative capacity of skeletal muscle (46) and pancreatic islet cells of diabetic rats (47).

\section{Adverse Effect}

It is worth noting that OT can worsen immune injury at parturient women with latex allergy and bronchial asthma (72), chorioamnionitis (73), and premature birth (74). This is likely associated with the muscle contraction following OTR activation in these tissues $(18,75)$ and requires special attention to the application of OT in parturient women with related disease histories. 


\section{RELATIONSHIP BETWEEN THE OSS AND OTHER NEUROENDOCRINE REGULATORY SYSTEMS}

The neuroendocrine regulation of immune activities has been considered as a function of several hypothalamic neuroendocrine axes, particularly the hypothalamic-pituitary-adrenal (HPA) axis, hypothalamic-pituitary-thyroid (HPT) axis, and the hypothalamic-pituitary-gonadal (HPG) axis. Changes in their activity can change the secretion of glucocorticoids (GC), thyroid hormone, sex steroid hormone, growth hormone (GH) prolactin (PRL), and vasopressin (VP) and thus profoundly affect lymphocyte homeostasis, self-tolerance, and immune pathological processes $(76,77)$. Importantly, there are close associations between activities of the OSS and these axes in the neuroendocrine regulation of the immune system. Additionally, the contribution of peripherally produced OT, particularly intrathymic OT, to the OT-associated immune activity should also influence the immune functions of the OSS.

\section{The OSS and Hypothalamic- Adenohypophysial-Immune Axes in Immune Regulation}

The immune regulatory roles of the adenohypophysial hormones $(2,63)$ are different from the neurohypophysial hormones as indicated by the effects of different types of pituitary lobectomy in rodents on antibody-mediated antimicrobial effects (78) and on antibody- and cell-mediated antiparasite effects $(13,79)$. Moreover, the OSS has close interactions with the HPA, HPT, and HPG axes (Figure 1A).

\section{The OSS and HPA Axis}

The immune function of HPA axis is mainly at suppression of immune reactions by offsetting the inflammatory reaction while activating anti-inflammatory processes (80-82). Experiments in rats further revealed that GC can rapidly inhibit the hypothalamic neuroendocrine activities including the secretion of $\mathrm{CRH}$ and OT (83). By contrast, OT can inhibit the activation of HPA axis induced by some stress stimuli (84) and their associated maternal depression (85) in rats. This is consistent with the finding that maternal separation decreased rat OSS activity $(85,86)$ while increasing the activity of HPA axis in calves (87). However, the OSS and HPA axis could work synergistically through suppression of inflammatory reactions by corticosteroids and OT, respectively (Figure 1B).

\section{The OSS and HPT Axis}

Thyrotropin-releasing hormone can directly regulate the immune activity as seen in mouse allergic encephalomyelitis (88) and in patients with Hashimoto's thyroiditis and primary hypothyroidism (89). It is also reported that triiodothyronine plays a critical role in controlling the maturation and antitumor functions of mouse dendritic cells and stimulation of cytotoxic T-cell responses (90). There is also evidence showing a close interaction between the OSS and the HPT axis. For example, high dose of triiodothyronine can increase OT mRNA levels in rat PVN (91) and OT release from rat pituitary (92). On the contrary, OT can reduce the response of pituitary thyroid-stimulating hormone cells to TRH and then reduce the release of thyroid hormone in rats (31) (Figure 1C).

\section{The OSS and HPG Axis}

The HPG axis is mainly involved in immune responses during sexual activity, menstrual cycle, and pregnancy (93). Estrogen can activate the immune response and even cause autoimmune diseases, such as lupus erythematosus, while androgen plays a role in human immune suppression (94). On the one hand, OT can stimulate the secretion of gonadotropin-releasing hormone directly by activating rat gonadotropin-releasing hormone neurons (95). On the other hand, the OSS is modulated by sex steroid hormones. For example, allopregnanolone suppresses (56) and estrogen increases (96) the activity of magnocellular OT neurons and/or OT secretion (Figure 1D). Noteworthy is that the interactions between the OSS and HPG axis could vary in females at reproductive age due to the variations of hormonal interactions at different stages of reproduction $(70,97)$.

\section{Comparison of Immune Regulatory Effects of VP versus OT}

The VP-secreting system (VSS) and OSS coexist in the HNS (68), and thus, the VSS could also be involved in the immune effects of rat neurointermediate lobectomy $(12,13)$. In fact, the VSS does have certain immune functions that are often opposite to the OSS (68). For example, in rat tissue culture, VP inhibits and OT facilitates the growth of thymus gland (98). Moreover, the immune functions of the VSS are narrower than that of the OSS. For example, the distribution of OTRs in the immune system is more extensive than that of VP receptors as seen in rats (99) and in mice (21). In contrast to the extensive immune functions of the OSS (Table 1), blocking VP signaling can only block the production of interferon- $\gamma$ by mouse spleen lymphocytes specifically and reversibly (100) along with a few of other functions (68).

Noteworthy are the following exceptions. (1) The VSS can also inhibit immune reaction at brain levels (101) and that is likely due to VP-evoked activation of the HPA axis (82). (2) The OSS and VSS may promote the maturation of immune system sequentially. That is, OT promotes T-cell differentiation in the thymus (16), and VP further facilitates their maturation in the spleen (100). Finally, OT can increase the activity of VP neurons (60), and thus, the functions of VSS can be considered as a supplement to the OSS in immune regulation.

\section{Relationship between the OSS and Other Neuroendocrine Activities}

In addition to the three major hypothalamic neuroendocrine axes and the VSS, other hypophysial hormones, such as GH and $\mathrm{PRL}$, are also involved in neuroendocrine regulation of immune responses (Figure 1E). GH and PRL can improve the proliferation and transplantation of the thymic cells and exert immune promoting effects (102). These two hormones also have close interaction with the OSS. It has been reported that application of $\mathrm{OT}$ in rat cerebral ventricles promotes the secretion of GH (103); 
OT can act on rat adenohypophysis to increase the secretion of PRL that reversely promotes the production of OT (103). This immune regulatory effect of OT via $\mathrm{GH}$ and PRL is consistent with the suppressive effect of neurointermediate lobectomy on rat thymus development $(12,13)$ and supports that OT is an essential hormone in the development and functions of the immune system.

\section{Intrathymic OT versus the OSS in Immune Regulation}

Both OT and OTR are expressed in mouse bone marrow (17) and in the thymus $(104,105)$ as well as many other components of the immune system $(106,107)$. Thus, peripheral OT has also some important immune functions (Figure 1F). For example, the intrathymic OT can dually regulate $\mathrm{T}$ cell-negative and -positive selections (108). Thymic epithelium can present OT and elicit clone deletion of self-reactive T-cells (1), thereby eliciting central immune self-tolerance of T-cells to OT and other hypophysial hormones (108). This function, as well as OT effects on rat bone marrow development (19), indicates that locally produced OT has important role in the maturation of immune system. However, as the thymus involutes over time, the immune functions of local OT mainly serve as a supplemental factor to OSS regulation of the immune system at local levels (77) through hidden secretion (108) or autocrine/paracrine effects (17).

\section{REFERENCES}

1. Geenen V. Thymus-dependent $T$ cell tolerance of neuroendocrine functions: principles, reflections, and implications for tolerogenic/negative self-vaccination. Ann N Y Acad Sci (2006) 1088:284-96. doi:10.1196/ annals. 1366.009

2. Verburg-van Kemenade BM, Cohen N, Chadzinska M. Neuroendocrineimmune interaction: evolutionarily conserved mechanisms that maintain allostasis in an ever-changing environment. Dev Comp Immunol (2017) 66:2-23. doi:10.1016/j.dci.2016.05.015

3. Wang P, Yang HP, Tian S, Wang L, Wang SC, Zhang F, et al. Oxytocinsecreting system: a major part of the neuroendocrine center regulating immunologic activity. J Neuroimmunol (2015) 289:152-61. doi:10.1016/j. jneuroim.2015.11.001

4. Besedovsky H, Sorkin E. Network of immune-neuroendocrine interactions. Clin Exp Immunol (1977) 27(1):1-12.

5. Ficek W. The physiological relationship between the hypothalamus and thymus of Wistar rats. I. Some morphological and microstructural changes in the hypothalamus in newborn rats following thymectomy. Gegenbaurs Morphol Jahrb (1982) 128(5):732-40.

6. Sominsky L, Fuller EA, Bondarenko E, Ong LK, Averell L, Nalivaiko E, et al. Functional programming of the autonomic nervous system by early life immune exposure: implications for anxiety. PLoS One (2013) 8(3):e57700. doi:10.1371/journal.pone.0057700

7. Buisman-Pijlman FT, Sumracki NM, Gordon JJ, Hull PR, Carter CS, Tops M. Individual differences underlying susceptibility to addiction: role for the endogenous oxytocin system. Pharmacol Biochem Behav (2014) 119:22-38. doi:10.1016/j.pbb.2013.09.005

8. Pittman QJ.A neuro-endocrine-immune symphony. JNeuroendocrinol (2011) 23(12):1296-7. doi:10.1111/j.1365-2826.2011.02176.x

9. Eliava M, Melchior M, Knobloch-Bollmann HS, Wahis J, da Silva Gouveia M, Tang Y, et al. A new population of parvocellular oxytocin neurons controlling magnocellular neuron activity and inflammatory pain processing. Neuron (2016) 89(6):1291-304. doi:10.1016/j.neuron.2016. 01.041

\section{CONCLUSION}

The OSS plays a key role in the neuroendocrine-immune network. It not only has direct regulatory effects on the development and functions of the immune system but also exerts functions of immune defense and homeostasis through coordinating the activity of the whole neuroendocrine-immune network as well as peripherally produced OT (Figure 1). The main question remaining to be answered is still the details of its relationship with other components in the neuroendocrine-immune network and peripherally produced OT under different types and extents of immune challenges. Answering these questions has great theoretical significance and broad potential for medical translation.

\section{AUTHOR CONTRIBUTIONS}

TL and PW wrote the first draft; SW participated in the revision; and YFW designed the review and made the final revision.

\section{ACKNOWLEDGMENTS}

This work was sponsored by the National Natural Science Foundation of China (grant no. 31471113, Y-FW) and the higher education talents funds of Heilongjiang province (grant no. 002000154). The funders had no role in the content of the text, decision to publish, or preparation of the manuscript.

10. Yang H, Wang L, Ju G. Evidence for hypothalamic paraventricular nucleus as an integrative center of neuroimmunomodulation. Neuroimmunomodulation (1997) 4(3):120-7.

11. Sendemir E, Kafa IM, Schafer HH, Jirikowski GF. Altered oxytocinergic hypothalamus systems in sepsis. JChem Neuroanat (2013) 52:44-8. doi:10.1016/j.jchemneu.2013.05.001

12. Quintanar-Stephano A, Kovacs K, Berczi I. Effects of neurointermediate pituitary lobectomy on humoral and cell-mediated immune responses in the rat. Neuroimmunomodulation (2004) 11(4):233-40. doi:10.1159/000078441

13. Campos-Rodriguez R, Quintanar-Stephano A, Jarillo-Luna RA, OliverAguillon G, Ventura-Juarez J, Rivera-Aguilar V, et al. Hypophysectomy and neurointermediate pituitary lobectomy reduce serum immunoglobulin M (IgM) and IgG and intestinal IgA responses to Salmonella enterica serovar Typhimurium infection in rats. Infect Immun (2006) 74(3):1883-9. doi:10.1128/IAI.74.3.1883-1889.2006

14. Elabd C, Basillais A, Beaupied H, Breuil V, Wagner N, Scheideler M, et al. Oxytocin controls differentiation of human mesenchymal stem cells and reverses osteoporosis. Stem Cells (2008) 26(9):2399-407. doi:10.1634/ stemcells.2008-0127

15. Kim YS, Ahn Y, Kwon JS, Cho YK, Jeong MH, Cho JG, et al. Priming of mesenchymal stem cells with oxytocin enhances the cardiac repair in ischemia/reperfusion injury. Cells Tissues Organs (2012) 195(5):428-42. doi:10.1159/000329234

16. Hansenne I. Thymic transcription of neurohypophysial and insulin-related genes: impact upon T-cell differentiation and self-tolerance. JNeuroendocrinol (2005) 17(5):321-7. doi:10.1111/j.1365-2826.2005.01301.x

17. Colaianni G, Sun L, Zaidi M, Zallone A. Oxytocin and bone. Am J Physiol Regul Integr Comp Physiol (2014) 307(8):R970-7. doi:10.1152/ajpregu. 00040.2014

18. Kim SH, MacIntyre DA, Hanyaloglu AC, Blanks AM, Thornton S, Bennett PR, et al. The oxytocin receptor antagonist, Atosiban, activates pro-inflammatory pathways in human amnion via G signaling. Mol Cell Endocrinol (2016) 420:11-23. doi:10.1016/j.mce.2015.11.012

19. Forostyak O, Butenko O, Anderova M, Forostyak S, Sykova E, Verkhratsky A, et al. Specific profiles of ion channels and ionotropic receptors define 
adipose- and bone marrow derived stromal cells. Stem Cell Res (2016) 16(3):622-34. doi:10.1016/j.scr.2016.03.010

20. Noiseux N, Borie M, Desnoyers A, Menaouar A, Stevens LM, Mansour S, et al. Preconditioning of stem cells by oxytocin to improve their therapeutic potential. Endocrinology (2012) 153(11):5361-72. doi:10.1210/ en.2012-1402

21. Hansenne I, Rasier G, Charlet-Renard C, DeFresne MP, Greimers R, Breton $\mathrm{C}$, et al. Neurohypophysial receptor gene expression by thymic $\mathrm{T}$ cell subsets and thymic T cell lymphoma cell lines. Clin Dev Immunol (2004) 11(1):45-51. doi:10.1080/10446670410001670481

22. Hansenne I, Rasier G, Pequeux C, Brilot F, Renard C, Breton C, et al. Ontogenesis and functional aspects of oxytocin and vasopressin gene expression in the thymus network. J Neuroimmunol (2005) 158(1-2):67-75. doi:10.1016/j.jneuroim.2004.08.007

23. Kim YS, Kwon JS, Hong MH, Kim J, Song CH, Jeong MH, et al. Promigratory activity of oxytocin on umbilical cord blood-derived mesenchymal stem cells. Artif Organs (2010) 34(6):453-61. doi:10.1111/j.1525-1594.2009. 00894.x

24. Dostal M, Zivny J, Harting P, Dejmek J, Steerenberg PA, van Loveren H, et al. Effects of labour and medication on major lymphocyte subsets in cord. Biomarkers (1997) 2(6):361-6. doi:10.1080/135475097231454

25. Oliveira-Pelegrin GR, Saia RS, Carnio EC, Rocha MJ. Oxytocin affects nitric oxide and cytokine production by sepsis-sensitized macrophages. Neuroimmunomodulation (2013) 20(2):65-71. doi:10.1159/000345044

26. Hamasaki MY, Barbeiro HV, Barbeiro DF, Cunha DM, Koike MK, Machado $\mathrm{MC}$, et al. Neuropeptides in the brain defense against distant organ damage. J Neuroimmunol (2016) 290:33-5. doi:10.1016/j.jneuroim.2015. 11.014

27. Mravec B, Lackovicova L, Pirnik Z, Bizik J, Bundzikova J, Hulin I, et al. Brain response to induced peripheral cancer development in rats: dual fos-tyrosine hydroxylase and fos-oxytocin immunohistochemistry. Endocr Regul (2009) 43(1):3-11. doi:10.4149/endo_2009_01_3

28. Matsuura T, Kawasaki M, Hashimoto H, Ishikura T, Yoshimura M, Ohkubo JI, et al. Fluorescent visualisation of oxytocin in the hypothalamo-neurohypophysial/-spinal pathways after chronic inflammation in oxytocin-monomeric red fluorescent protein 1 transgenic rats. J Neuroendocrinol (2015) 27(7):636-46. doi:10.1111/jne.12290

29. Pequeux C, Breton C, Hagelstein MT, Geenen V, Legros JJ. Oxytocin receptor pattern of expression in primary lung cancer and in normal human lung. Lung Cancer (2005) 50(2):177-88. doi:10.1016/j.lungcan.2005. 05.027

30. Sherman SK, Maxwell JE, Carr JC, Wang D, Bellizzi AM, Sue O, et al. Gene expression accurately distinguishes liver metastases of small bowel and pancreas neuroendocrine tumors. Clin Exp Metastasis (2014) 31(8):935-44. doi:10.1007/s10585-014-9681-2

31. Carrera-Gonzalez MP, Ramirez-Exposito MJ, de Saavedra JM, SanchezAgesta R, Mayas MD, Martinez-Martos JM. Hypothalamus-pituitary-thyroid axis disruption in rats with breast cancer is related to an altered endogenous oxytocin/insulin-regulated aminopeptidase (IRAP) system. Tumour Biol (2011) 32(3):543-9. doi:10.1007/s13277-010-0149-y

32. Erbas O, Taskiran D, Oltulu F, Yavasoglu A, Bora S, Bilge O, et al. Oxytocin provides protection against diabetic polyneuropathy in rats. Neurol Res (2017) 39(1):45-53. doi:10.1080/01616412.2016.1249630

33. Iseri SO, Sener G, Saglam B, Gedik N, Ercan F, Yegen BC. Oxytocin ameliorates oxidative colonic inflammation by a neutrophil-dependent mechanism. Peptides (2005) 26(3):483-91. doi:10.1016/j.peptides.2004. 10.005

34. Deing V, Roggenkamp D, Kuhnl J, Gruschka A, Stab F, Wenck H, et al. Oxytocin modulates proliferation and stress responses of human skin cells: implications for atopic dermatitis. Exp Dermatol (2013) 22(6):399-405. doi:10.1111/exd.12155

35. Ross KM, McDonald-Jones G, Miller GE. Oxytocin does not attenuate the ex vivo production of inflammatory cytokines by lipopolysaccharideactivated monocytes and macrophages from healthy male and female don ors. Neuroimmunomodulation (2013) 20(5):285-93. doi:10.1159/000351610

36. Jankowski M, Bissonauth V, Gao L, Gangal M, Wang D, Danalache B, et al. Anti-inflammatory effect of oxytocin in rat myocardial infarction. Basic Res Cardiol (2010) 105(2):205-18. doi:10.1007/s00395-009-0076-5
37. Clodi M, Vila G, Geyeregger R, Riedl M, Stulnig TM, Struck J, et al. Oxytocin alleviates the neuroendocrine and cytokine response to bacterial endotoxin in healthy men. Am J Physiol Endocrinol Metab (2008) 295(3):E686-91. doi:10.1152/ajpendo.90263.2008

38. Kurlaev PP, Gavrilenko VG. [Correction of hyperglycemia in diabetic patients with postinjection abscesses]. Khirurgiia (Mosk) (2001) (7):39-41.

39. Gurtner GC, Werner S, Barrandon Y, Longaker MT. Wound repair and regeneration. Nature (2008) 453(7193):314-21. doi:10.1038/nature07039

40. Iseri SO, Gedik IE, Erzik C, Uslu B, Arbak S, Gedik N, et al. Oxytocin ameliorates skin damage and oxidant gastric injury in rats with thermal trauma. Burns (2008) 34(3):361-9. doi:10.1016/j.burns.2007.03.022

41. Iseri SO, Dusunceli F, Erzik C, Uslu B, Arbak S, Yegen BC. Oxytocin or social housing alleviates local burn injury in rats. J Surg Res (2010) 162(1):122-31. doi:10.1016/j.jss.2009.02.018

42. Lopatina O, Yoshihara T, Nishimura T, Zhong J, Akther S, Fakhrul AA, et al. Anxiety- and depression-like behavior in mice lacking the CD157/BST1 gene, a risk factor for Parkinson's disease. Front Behav Neurosci (2014) 8:133. doi:10.3389/fnbeh.2014.00133

43. Kim YS, Kwon JS, Hong MH, Kang WS, Jeong HY, Kang HJ, et al. Restoration of angiogenic capacity of diabetes-insulted mesenchymal stem cells by oxytocin. BMC Cell Biol (2013) 14(1):38. doi:10.1186/1471-2121-14-38

44. Kobayashi H, Yasuda S, Bao N, Iwasa M, Kawamura I, Yamada Y, et al. Postinfarct treatment with oxytocin improves cardiac function and remodeling via activating cell-survival signals and angiogenesis. J Cardiovasc Pharmacol (2009) 54(6):510-9. doi:10.1097/FJC.0b013e3181bfac02

45. Moller A, Hansen BL, Hansen GN, Hagen C. Autoantibodies in sera from patients with multiple sclerosis directed against antigenic determinants in pituitary growth hormone-producing cells and in structures containing vasopressin/oxytocin. J Neuroimmunol (1985) 8(2-3):177-84. doi:10.1016/ S0165-5728(85)80058-8

46. Elabd C, Cousin W, Upadhyayula P, Chen RY, Chooljian MS, Li J, et al. Oxytocin is an age-specific circulating hormone that is necessary for muscle maintenance and regeneration. Nat Commun (2014) 5:4082. doi:10.1038/ ncomms 5082

47. Elabd SK, Sabry I, Mohasseb M, Algendy A. Oxytocin as a novel therapeutic option for type I diabetes and diabetic osteopathy. Endocr Regul (2014) 48(2):87-102. doi:10.4149/endo_2014_02_87

48. Klein BY, Tamir H, Hirschberg DL, Ludwig RJ, Glickstein SB, Myers MM, et al. Oxytocin opposes effects of bacterial endotoxin on ER-stress signaling in Caco2BB gut cells. Biochim Biophys Acta (2016) 1860(2):402-11. doi:10.1016/j.bbagen.2015.10.025

49. Fekete EM, Antoni MH, Lopez C, Mendez AJ, Szeto A, Fletcher MA, et al. Stress buffering effects of oxytocin on HIV status in low-income ethnic minority women. Psychoneuroendocrinology (2011) 36(6):881-90. doi:10.1016/j.psyneuen.2010.12.003

50. Benrick A, Schele E, Pinnock SB, Wernstedt-Asterholm I, Dickson SL, Karlsson-Lindahl L, et al. Interleukin-6 gene knockout influences energy balance regulating peptides in the hypothalamic paraventricular and supraoptic nuclei. J Neuroendocrinol (2009) 21(7):620-8. doi:10.1111/j. 1365-2826.2009.01879.x

51. Trotter RN, Stornetta RL, Guyenet PG, Roberts MR. Transneuronal mapping of the CNS network controlling sympathetic outflow to the rat thymus. Auton Neurosci (2007) 131(1-2):9-20. doi:10.1016/j.autneu.2006.06.001

52. Santisteban MM, Ahmari N, Carvajal JM, Zingler MB, Qi Y, Kim S, et al. Involvement of bone marrow cells and neuroinflammation in hypertension. Circ Res (2015) 117(2):178-91. doi:10.1161/CIRCRESAHA.117.305853

53. Nilaver G, Rosenbaum LC, Hellstrom KE, Hellstrom I, Neuwelt EA. Identification of neurophysin immunoreactivity in hypothalamus by a monoclonal antibody to a carcinoma cell surface antigen. Neuroendocrinology (1990) 51(5):565-71. doi:10.1159/000125392

54. Huitinga I, van der Cammen M, Salm L, Erkut Z, van Dam A, Tilders F, et al. IL-1beta immunoreactive neurons in the human hypothalamus: reduced numbers in multiple sclerosis. J Neuroimmunol (2000) 107(1):8-20. doi:10.1016/S0165-5728(00)00248-4

55. Langford D, Baron D, Joy J, Del Valle L, Shack J. Contributions of HIV infection in the hypothalamus and substance abuse/use to HPT dysregulation. Psychoneuroendocrinology (2011) 36(5):710-9. doi:10.1016/j. psyneuen.2010.10.005 
56. Brunton PJ, Bales J, Russell JA. Allopregnanolone and induction of endogenous opioid inhibition of oxytocin responses to immune stress in pregnant rats. JNeuroendocrinol (2012) 24(4):690-700. doi:10.1111/ j.1365-2826.2012.02295.x

57. Du D, Jiang M, Liu M, Wang J, Xia C, Guan R, et al. Microglial P2X(7) receptor in the hypothalamic paraventricular nuclei contributes to sympathoexcitatory responses in acute myocardial infarction rat. Neurosci Lett (2015) 587:22-8. doi:10.1016/j.neulet.2014.12.026

58. Summy-Long JY, Hu S, Long A, Phillips TM. Interleukin-1beta release in the supraoptic nucleus area during osmotic stimulation requires neural function. J Neuroendocrinol (2008) 20(11):1224-32. doi:10.1111/ j.1365-2826.2008.01783.x

59. Ferrini M, Wang C, Swerdloff RS, Sinha Hikim AP, Rajfer J, GonzalezCadavid NF. Aging-related increased expression of inducible nitric oxide synthase and cytotoxicity markers in rat hypothalamic regions associated with male reproductive function. Neuroendocrinology (2001) 74(1):1-11. doi:10.1159/000054665

60. Wang YF, Hatton GI. Mechanisms underlying oxytocin-induced excitation of supraoptic neurons: prostaglandin mediation of actin polymerization. J Neurophysiol (2006) 95(6):3933-47. doi:10.1152/jn.01267.2005

61. Wang SC, Zhang F, Zhu H, Lv C, Liu X, Wang Y-F, et al. Suckling-induced burst discharges of supraoptic oxytocin neurons in rats: prostaglandin mediation of oxytocin actions. Int J Adv Res (2016) 4(7):1111-22. doi:10.21474/ IJAR01/947

62. Okere CO, Wang YF, Higuchi T, Negoro H, Okutani F, Takahashi S, et al. The effect of systemic and central nitric oxide administration on milk availability in lactating rats. Neuroreport (1996) 8(1):243-7. doi:10.1097/ 00001756-199612200-00049

63. Kelley KW, McCusker RH. Getting nervous about immunity. Semin Immunol (2014) 26(5):389-93. doi:10.1016/j.smim.2014.01.011

64. Caldwell JD, Walker CH, Pedersen CA, Mason GA. Sexual activity decreases oxytocin receptor densities in the thymus. Life Sci (1993) 52(22):1781-6. doi:10.1016/0024-3205(93)90467-H

65. Ndiaye K, Poole DH, Pate JL. Expression and regulation of functional oxytocin receptors in bovine T lymphocytes. Biol Reprod (2008) 78(4):786-93. doi:10.1095/biolreprod.107.065938

66. Hatton GI, Wang YF. Neural mechanisms underlying the milk ejection burst and reflex. Prog Brain Res (2008) 170:155-66. doi:10.1016/ S0079-6123(08)00414-7

67. Wang YF, Zhu H. [Mechanisms underlying astrocyte regulation of hypothalamic neuroendocrine neuron activity]. Sheng Li Ke Xue Jin Zhan (2014) 45(3):177-84.

68. Hou D, Jin J, Li J, Lian J, Liu M, Liu X, et al. Model roles of the hypothalamoneurohypophysial system in neuroscience study. Biochem Pharmacol (Los Angel) (2016) 5(211):13-28. doi:10.4172/2167-0501.1000211

69. Summy-Long JY, Bui V, Gestl S, Kadekaro M. Nitric oxide, interleukin and prostaglandin interactions affecting the magnocellular system. Brain Res (2002) 940(1-2):10-20. doi:10.1016/S0006-8993(02)02556-8

70. Brunton PJ, Sabatier N, Leng G, Russell JA. Suppressed oxytocin neuron responses to immune challenge in late pregnant rats: a role for endogenous opioids. Eur JNeurosci (2006) 23(5):1241-7. doi:10.1111/ j.1460-9568.2006.04614.x

71. Matelski L, Van de Water J. Risk factors in autism: thinking outside the brain. J Autoimmun (2016) 67:1-7. doi:10.1016/j.jaut.2015.11.003

72. Liccardi G, Bilo M, Mauro C, Salzillo A, Piccolo A, D’Amato M, et al. Oxytocin: an unexpected risk for cardiologic and broncho-obstructive effects, and allergic reactions in susceptible delivering women. Multidiscip Respir Med (2013) 8(1):67. doi:10.1186/2049-6958-8-67

73. Saji F, Samejima Y, Kamiura S, Sawai K, Shimoya K, Kimura T. Cytokine production in chorioamnionitis. J Reprod Immunol (2000) 47(2):185-96. doi:10.1016/S0165-0378(00)00064-4

74. Chang EY, Zhang J, Sullivan S, Newman R, Singh I. N-acetylcysteine prevents preterm birth by attenuating the LPS-induced expression of contractile associated proteins in an animal model. J Matern Fetal Neonatal Med (2012) 25(11):2395-400. doi:10.3109/14767058.2012.697942

75. Amrani Y, Syed F, Huang C, Li K, Liu V, Jain D, et al. Expression and activation of the oxytocin receptor in airway smooth muscle cells: regulation by TNFalpha and IL-13. Respir Res (2010) 11:104. doi:10.1186/1465-992111-104
76. Barnard A, Layton D, Hince M, Sakkal S, Bernard C, Chidgey A, et al. Impact of the neuroendocrine system on thymus and bone marrow function. Neuroimmunomodulation (2008) 15(1):7-18. doi:10.1159/000135619

77. Quintanar JL, Guzman-Soto I. Hypothalamic neurohormones and immune responses. Front Integr Neurosci (2013) 7:56. doi:10.3389/fnint.2013.00056

78. Quintanar-Stephano A, Abarca-Rojano E, Jarillo-Luna RA, Rivera-Aguilar V, Ventura-Juarez J, Berczi I, et al. Hypophysectomy and neurointermediate pituitary lobectomy decrease humoral immune responses to T-independent and T-dependent antigens. J Physiol Biochem (2010) 66(1):7-13. doi:10.1007/ s13105-010-0004-z

79. Quintanar-Stephano A, Hernandez-Cervantes R, Moreno-Mendoza N, Escobedo G, Carrero JC, Nava-Castro KE, et al. The endocrine-immune network during taeniosis by Taenia solium: the role of the pituitary gland. Exp Parasitol (2015) 159:233-44. doi:10.1016/j.exppara.2015.10.003

80. Correa SG, Rodriguez-Galan MC, Sotomayor CE. [Basic aspects of neuroendocrinoimmunology]. Rev Fac Cien Med Univ Nac Cordoba (1999) 56(2):9-20.

81. Weismuller K, Bauer M, Hofer S, Weigand MA. [The neuroendocrine axis and the pathophysiology of sepsis]. Anasthesiol Intensivmed Notfallmed Schmerzther (2010) 45(9):574-578; quiz 579. doi:10.1055/s-0030-1265750

82. Uchoa ET, Aguilera G, Herman JP, Fiedler JL, Deak T, de Sousa MB. Novel aspects of glucocorticoid actions. J Neuroendocrinol (2014) 26(9):557-72. doi: $10.1111 /$ jne. 12157

83. Di S, Tasker JG. Rapid synapse-specific regulation of hypothalamic magnocellular neurons by glucocorticoids. Prog Brain Res (2008) 170:379-88. doi:10.1016/S0079-6123(08)00431-7

84. Neumann ID, Wigger A, Torner L, Holsboer F, Landgraf R. Brain oxytocin inhibits basal and stress-induced activity of the hypothalamopituitary-adrenal axis in male and female rats: partial action within the paraventricular nucleus. J Neuroendocrinol (2000) 12(3):235-43. doi:10.1046/j.1365-2826.2000.00442.x

85. Wang Y-F, Hatton GI. Oxytocin, lactation and postpartum depression. Front Neurosci (2009) 3:252-3.

86. Liu X, Jia S, Zhang Y, Wang Y-F. Pulsatile but not tonic secretion of oxytocin plays the role of anti-precancerous lesions of the mammary glands in rat dams separated from the pups during lactation. M J Neuro (2016) 1(1):002.

87. Hickey MC, Drennan M, Earley B. The effect of abrupt weaning of suckler calves on the plasma concentrations of cortisol, catecholamines, leukocytes, acute-phase proteins and in vitro interferon-gamma production. J Anim Sci (2003) 81(11):2847-55. doi:10.2527/2003.81112847x

88. Brod SA, Bauer V. Ingested (oral) thyrotropin releasing factor (TRH) inhibits EAE. Cytokine (2013) 61(1):323-8. doi:10.1016/j.cyto.2012.10.015

89. Marchiori RC, Pereira LA, Naujorks AA, Rovaris DL, Meinerz DF, Duarte $\mathrm{MM}$, et al. Improvement of blood inflammatory marker levels in patients with hypothyroidism under levothyroxine treatment. BMC Endocr Disord (2015) 15:32. doi:10.1186/s12902-015-0032-3

90. Alamino VA, Mascanfroni ID, Montesinos MM, Gigena N, Donadio AC, Blidner AG, et al. Antitumor responses stimulated by dendritic cells are improved by triiodothyronine binding to the thyroid hormone receptor beta. Cancer Res (2015) 75(7):1265-74. doi:10.1158/0008-5472.CAN14-1875

91. Dellovade TL, Zhu YS, Pfaff DW. Thyroid hormones and estrogen affect oxytocin gene expression in hypothalamic neurons. J Neuroendocrinol (1999) 11(1):1-10. doi:10.1046/j.1365-2826.1999.00250.x

92. Ciosek J, Drobnik J. Vasopressin and oxytocin release and the thyroid function. J Physiol Pharmacol (2004) 55(2):423-41.

93. Segner H, Verburg-van Kemenade BM, Chadzinska M. The immunomodulatory role of the hypothalamus-pituitary-gonad axis: proximate mechanism for reproduction-immune trade offs? Dev Comp Immunol (2017) 66:43-60. doi:10.1016/j.dci.2016.07.004

94. Gubbels Bupp MR. Sex, the aging immune system, and chronic disease. Cell Immunol (2015) 294(2):102-10. doi:10.1016/j.cellimm.2015.02.002

95. Caligioni CS, Oliver C, Jamur MC, Franci CR. Presence of oxytocin receptors in the gonadotrophin-releasing hormone $(\mathrm{GnRH})$ neurones in female rats: a possible direct action of oxytocin on GnRH neurones. J Neuroendocrinol (2007) 19(6):439-48. doi:10.1111/j.1365-2826.2007.01550.x

96. Acevedo-Rodriguez A, Mani SK, Handa RJ. Oxytocin and estrogen receptor beta in the brain: an overview. Front Endocrinol (2015) 6:160. doi:10.3389/ fendo.2015.00160 
97. Liu XY, Hou D, Wang J, Lv C, Jia S, Zhang Y, et al. Expression of glial fibrillary acidic protein in astrocytes of rat supraoptic nucleus throughout estrous cycle. Neuro Endocrinol Lett (2016) 37(1):41-5.

98. Ficek W. Physiological dependency between the hypothalamus and the thymus of Wistar rats. IV. Organotypic culture of the thymus in the presence of hypophyseal hormones, vasopressin, and oxytocin. Gegenbaurs Morphol Jahrb (1983) 129(4):445-58.

99. Elands J, Resink A, De Kloet ER. Neurohypophyseal hormone receptors in the rat thymus, spleen, and lymphocytes. Endocrinology (1990) 126(5):2703-10. doi:10.1210/endo-126-5-2703

100. Johnson HM, Torres BA. A novel arginine vasopressin-binding peptide that blocks arginine vasopressin modulation of immune function. J Immunol (1988) 141(7):2420-3.

101. Decker DA, GrantC, OhL, Becker PM, Young D, Jordan S. Immunomodulatory effects of H.P. Acthar Gel on B cell development in the NZB/W F1 mouse model of systemic lupus erythematosus. Lupus (2014) 23(8):802-12. doi:10.1177/0961203314531840

102. Savino W, Mendes-da-Cruz DA, Lepletier A, Dardenne M. Hormonal control of T-cell development in health and disease. Nat Rev Endocrinol (2016) 12(2):77-89. doi:10.1038/nrendo.2015.168

103. Lumpkin MD, Samson WK, McCann SM. Hypothalamic and pituitary sites of action of oxytocin to alter prolactin secretion in the rat. Endocrinology (1983) 112(5):1711-7. doi:10.1210/endo-112-5-1711

104. Geenen V, Legros JJ, Franchimont P, Baudrihaye M, Defresne MP, Boniver J. The neuroendocrine thymus: coexistence of oxytocin and neurophysin in the human thymus. Science (1986) 232(4749):508-11. doi:10.1126/ science.3961493

105. Bodey B, Bodey B Jr, Siegel SE, Kaiser HE. The role of the reticulo-epithelial (RE) cell network in the immuno-neuroendocrine regulation of intrathymic lymphopoiesis. Anticancer Res (2000) 20(3A):1871-88.

106. Gimpl G, Fahrenholz F. The oxytocin receptor system: structure, function, and regulation. Physiol Rev (2001) 81(2):629-83.

107. Kimura T, Saji F, Nishimori K, Ogita K, Nakamura H, Koyama M, et al. Molecular regulation of the oxytocin receptor in peripheral organs. J Mol Endocrinol (2003) 30(2):109-15. doi:10.1677/jme.0.0300109

108. Geenen V, Bodart G, Henry S, Michaux H, Dardenne O, Charlet-Renard C, et al. Programming of neuroendocrine self in the thymus and its defect in the development of neuroendocrine autoimmunity. Front Neurosci (2013) 7:187. doi:10.3389/fnins.2013.00187

Conflict of Interest Statement: The authors declare that the research was conducted in the absence of any commercial or financial relationships that could be construed as a potential conflict of interest.

Copyright (c) $2017 \mathrm{Li}$, Wang, Wang and Wang. This is an open-access article distributed under the terms of the Creative Commons Attribution License (CC BY). The use, distribution or reproduction in other forums is permitted, provided the original author(s) or licensor are credited and that the original publication in this journal is cited, in accordance with accepted academic practice. No use, distribution or reproduction is permitted which does not comply with these terms. 